The Journal of Animal \& Plant Sciences, 30(3): 2020, Page: 749-765

ISSN (print): 1018-7081; ISSN (online): 2309-8694

\title{
ISOLATION, CHARACTERIZATION AND EXPRESSION ANALYSIS OF PUTATIVE DROUGHT RESPONSIVE EXPRESSED SEQUENCED TAGS FROM GOSSYPIUM ARBOREUM ROOTS
}

\author{
A. Jamal ${ }^{1,2^{*}}$, M. N. Shahid ${ }^{3}$, B. Aftab ${ }^{4}$, A. K. Johargy ${ }^{1}$, M. S. Alshmemri ${ }^{1}$, B. Rashid ${ }^{2}$, and T. Husnain ${ }^{2}$ \\ ${ }^{1}$ College of Nursing, Umm Al-Qura University, Makkah-715, Kingdom of Saudi Arabia. \\ ${ }^{2}$ Plant Genomics Lab, Centre of Excellence in Molecular Biology, University of the Punjab, 87-West Canal Bank Road, \\ Thokar Niaz Baig, Lahore-53700, Pakistan. \\ ${ }^{3}$ Department of Botany, Division of Science and Technology, University of Education, Lahore, Pakistan. \\ ${ }^{4}$ Department of Biological Sciences, Faculty of Fisheries and Wildlife, University of Veterinary and Animal Sciences- \\ Ravi Campus, Pattoki-55300, Pakistan. \\ ${ }^{*}$ Corresponding author Address Email: adiljamalcemb@gmail.com, aajamal@uqu.edu.sa
}

\begin{abstract}
Cotton is an important economic fibre crop. Seasonal water shortages and long term water deficit can effect cotton yield. Current study aimed to explore the cotton root transcriptome under drought stress. mRNA extracted from cotton roots subjected to osmotic stress treatment (5\% gravimetric humidity) was used to construct cDNA library. Expressed sequence tags submitted to gene bank EST database (JK757087-JK757798) further annotated to predict the homology and function. Total 104 transcripts with an E-value less than $1 \mathrm{e}^{-33}$ revealed $82(78.84 \%)$ known homologs and 22 $(21.15 \%)$ with uncharacterized proteins. Gene ontology and KEGG analysis of these drought responsive ESTs elucidated their key role in biological regulation, molecular functions and cellular organelles. Expression pattern of 10 unigenes were validated by RT-qPCR in roots and leaves. These unigenes included WD repeat, FRIGIDA, peroxidase, E3 ubiquitin ligase, U-box domain, RNA binding, calcyclin binding, Glutathione S transferase, endochitinase and metallothionine like protein. cDNA library was successfully constructed from cotton roots and revealed several key drought responsive transcripts. Novel sequences identified in this study can be valuable resource for further exploration studies to exploit their role in genomics of drought responsive mechanism.
\end{abstract}

Key words: Drought stress; Expressed Sequence Tags (EST), Homology, KEGG, Orthologs, qRT-PCR. https://doi.org/10.36899/JAPS.2020.3.0088 Published online March 25, 2020

\section{INTRODUCTION}

Cotton is an important economic fibre crop, grown in tropical zones especially in U.S, Uzbekistan, China, India, Brazil, Pakistan and Turkey (Riaz et al., 2013). As stated by measurable surveys, India, USA, China, Brazil and Pakistan are top five principal cotton producing countries in the world (Statista 2019; OECDFAO 2019). Cotton production declined in India, China, USA and Pakistan mainly due to water shortage and pest problems (OECD-FAO 2019). Unfavourable environmental abiotic stresses are leading factors in decreasing agricultural productivity (Grayson, 2013). Indeed, cotton being as glycophyte shows higher degree tolerance to abiotic stresses. However, extreme natural factors like drought affect growth, productivity and as well fibre quality of cotton (Parida et al., 2007). The molecular biology approaches play key role in genome alteration of higher plants against environmental factors for better growth and yield (Edgerton, 2009; Lawlor 2013). Incapacitating abiotic factors that reduce the crops yield has been main area of discussion. Drought, key abiotic factor that significantly affects plant biomass and yield (Chaves and Oliveira, 2004). The cotton genome is large as compared to other plant species, making it challenging to study. Thus, key understanding of drought stress tolerance can disclose the variable expression and regulation of key genes that may augment cotton drought tolerance.

Drought includes a variety of plant responses, including stomatal regulation, gene expression alteration, build-up of abscisic acid, generation of osmotic compounds and production of defensin proteins that destroy free radicals, ROS or act as nucleic acid binding factors (Wang et al., 2003). These events are controlled by complex networks at molecular level that trigger stress responsive mechanism to restore homeostasis, defend and revive impaired cellular components (Ramachandra et al., 2004). Responses to abiotic factors are genetically intricate and also complicated to understand. Previously, gene expression encoding dehydrins, antioxidants involved in the generation of structural and functional metabolites were used for modification of stress tolerance in plants (Park et al., 2005). Currently, approaches to utilize genes with their role in signalling and monitoring 
networks and pathways have revealed remarkable potential (Umezawa et al., 2006).

Previous studies have focused on the cotton drought resistance on aboveground plant tissues while less knowledge have been documented on underground plant tissues. For instance, 3,517 unigenes were differentially expressed in Gossypium herbaceum leaves and roots of cotton with involvement of the 28 biological pathways significantly to drought stress (Ranjan and Sawant, 2015); cDNA library analysis of the 92 positive drought stress responsive clones with differential expression (Zhang et al., 2009); 6,047 high-quality expressed sequence tags (ESTs) from $G$. barbadense revealed enrichment of transcription factors and stressrelated genes (Zhou et al., 2016).

Roots are the vital organs of plants with key role in absorption and translocation of nutrients and water. Being as major connection between the plant and soil stresses, root generate specific chemical messenger from root to shoot that initiate stomatal closure and ultimately reduce evaporation losses (Davies and Zhang, 1991; Jia and Zhang, 2008). However, limited information prevails at molecular level regarding cotton root responses under water deficit stress (Graya and Brady, 2016). A key understanding of principal genes involved in osmotic stress is necessary for the plant development that sustain more yields under osmotic stress.

Sequenced and re-sequenced cotton genomes are simply the foundation; the main challenge is to discover the features of the genome to elucidate the biology. The next stage of cotton genomics will entirely expose these biologically genome active states, as has been made for other model crop plants where high density genetic and fine maps, SNP array platforms, transcript abundance epigenetic regulations and modifications (Ashraf et al., 2018). Recently, most promising molecular approach is transcriptome profiling for demonstrating how information obtained from sequence data can be transformed into an extensive knowledge of gene function. Genome sequence and latest approaches like NGS technology practiced and reported several reports in cotton using RNA-Seq analysis. For instance, cotton root transcriptome analysis under water deficit stress (Bowman et al., 2013; Zhang et al., 2016) has been reported. However, RNA-Seq technique being among latest molecular approaches to study gene annotation faces some challenges such as library construction hence screening cDNA libraries screening as high throughput approach is an efficient way to identify functional and stress-tolerance genes in cotton (Li et al., 2019) and other plant species (Wang et al., 2019; Dossa et al., 2019).

Despite of being the massive cotton genome sequence information using latest genomic approaches like whole genome sequencing and re-sequencing, still there large information gaps as compared to other model plants like tobacco and Arabidopsis. Hence, next era of cotton genomics require re-sequencing broad diversity panels, draft genome refinement including the development of high throughput functional genomics tools and integrating multidisciplinary approaches including transcriptomics, epigenomics, proteomics and bioinformatics to further explicate its genome and functional characterization.

Our lab has previously reported the abiotic stress responsive genes in Gossypium arboreum using multiple molecular approaches and tools (Maqbool et al., 2008; Barozai and Husnain 2012; Shahid et al.,2012). Previous findings revealed the elucidative role under multiple abiotic stresses. Taking into account the Gossypium arboreum as potential gene pool of abiotic stress responsive genes, present study was planned to explore the key putative drought responsive transcripts in cotton root by cDNA library. In this study, we report the identification and functional characterization of young root drought responsive based EST's of cotton.

\section{MATERIALS AND METHODS}

Plant growth, drought stress induction, RNA isolation and mRNA purification: Gossypium arboreum cv FDH786 was selected for evaluation. Delinted seeds were grown in a mixture of peat, sand, soil (1:1:1) under controlled environmental conditions in green house at $25 \pm 2{ }^{\circ} \mathrm{C}$; relative humidity $45-50 \%$ and $1500 \mu \mathrm{molm}^{2} \mathrm{~s}^{-1}$ light intensity provided by metal halide lamps $(400 \mathrm{~W})$. The water stress treatment was inducted following previous studies (Maqbool et al., 2007; Jamal et al., 2014). The amount of water held by the soil was measured as gravimetric humidity $(\mathrm{GH})$. Forty days old cotton seedlings following two moisture stress treatments $10 \%$ and $5 \% \mathrm{GH}$ along $15 \% \mathrm{GH}$ as control treatment were taken into study. Water stress treatment was maintained periodically for 15 days and monitored gravimetrically by weighing the pots daily. The fresh roots and leaves were harvested, immediately frozen and grinded in liquid nitrogen for RNA isolation. To construct the drought responsive cDNA library, RNA extraction was done form plants maintained at $5 \% \mathrm{GH}$.

The relative water content (RWC) of leaves were measured for the second fully expanded leaves. The RWC was measured as described earlier (Barrs and Weatherly, 1962).

RWC $(\%)=[($ fresh wt - dry wt $) /($ turgid wt - dry wt $)] \times$ 100

Total RNA isolation from the roots and leaves was performed as described earlier with minor modifications (Jakola et al., 2001). Isolated RNA was further treated with DNase I, RNase-free (Thermo Fisher Scientific, USA) to avoid genomic DNA impurity before the synthesis of mRNA. To check the integrity of RNA samples, RNA samples were electrophoresed on $0.9 \%$ agarose. RNA concentration was measured using 
spectrophotometer (ND-1000 NanoDrop Technologies, Inc.). RNA samples having A260/280 ratio of 1.8-2.0 were used further. mRNA extraction and purification was performed using oligotex mRNA mini kit (Qiagen, Valencia USA) following manufacturer directions.

cDNA library construction, clones amplification, Sequencing and bioinformatics: cDNA library was constructed using CloneMiner ${ }^{\mathrm{TM}}$ cDNA library construction kit (USA, Invitrogen) following manufacturer instructions. Blunt end ds cDNA was size fractioned using low melt agarose gel $(0.8 \%)$ with size ranged between $>100 \mathrm{bp}-<1 \mathrm{~kb}$. The ds cDNA was eluted using DNA gel extraction kit (Thermo Fisher Scientific, USA) following manufacturer guidelines. The eluted cDNA was proceeded for BP recombination reaction. Electroporation was performed for fractioned cDNA aliquot by adding to thawed ElectroMAX DH10B $\mathrm{TM} \mathrm{T}_{1}$ phage competent resistant cells. Electroporated cells were incubated at $37^{\circ} \mathrm{C}$ for $1 \mathrm{~h}$ at $200 \mathrm{rpm}$ for the expression of kanamycin. Incubated cells were further pooled with equal volume of sterile freezing media. These aliquots were prepared from pooled samples and stored at $-80^{\circ} \mathrm{C}$. Clones were screened from white colonies on agar plates with kanamycin selection. Positive transformants were confirmed by colony PCR. Colony PCR was performed using M13 sense and antisense primers following amplification program of initial denaturation at $94^{\circ} \mathrm{C}$ for $5 \mathrm{~min}$; denaturation at $94^{\circ} \mathrm{C}$, annealing at $52^{\circ} \mathrm{C}$ and extension at $72^{\circ} \mathrm{C}$ each of 35 cycles at $45 \mathrm{~s}, 45 \mathrm{~s}, 60 \mathrm{~s}$ respectively and final extension at $72^{\circ} \mathrm{C}$ for $10 \mathrm{~min}$.

For sequencing, isolated plasmid DNAs from randomly selected clones were used for Sanger sequencing. Isolated plasmids were extracted using alkaline lysis method (Sambrook et al., 1998).Clones were sequenced using cycle sequencing kit (ABI PRISM Foster, USA) on Applied Biosystems Sequencer model $3100 / 3700$. The vector and adaptor sequences present at both $5^{\prime}$ and $3^{\prime}$ of sequences were removed using Vec Screen online available tool (https://www.ncbi.nlm.nih.gov/tools/vecscreen/). NCBI database was used to study the non-redundant nucleotide sequence (BASTN) and non-redundant protein sequence (BLASTX) similarities between ESTs and other databases sequences. Unisequences with an E-value $<1 \mathrm{e}^{-}$ ${ }^{33}$ were compared to swissprot and blastx (Altschul et al., 1990). Analyzed blastx predicted sequence homology against Gossypium species were further used in Cotton Functional Genomics Database (CottonFGD) (https://cottonfgd.org/) to find the Gene ID of the respective sequences. The gene ids of the respective sequences saved were used for further annotation and functional assignments. The gene annotation (functions) of cotton was performed using PANTHER (ver 13) (http://pantherdb.org/) using corresponding Arabidopsis orthologs. KEGG Mapper (Kyoto Encyclopedia of Genes and Genomes) (Ogata et al., 1999) (http://www.genome.jp/kegg/mapper.html) was used to study the KEGG orthology and associated pathways online available.

Quantitative real time PCR analysis (RT-qPCR): Total RNA was treated with DNase I to avoid any genomic DNA residues. First strand cDNA was synthesized using cDNA synthesis kit (Fermentas, Germany). Primers were designed against using online available tool (http://bioinfo.ut.ee/primer3-0.4.0/) (Table 1) with selection of no primer dimer synthesis. Cotton GAPDH primer was used as reference gene for normalization (Zahur et al., 2012). Quantitative real time PCR was performed using iQ5 (Bio-Rad, USA) with IQTM SYBR Green supermix (Fermentas, USA). Amplification program consisted of $95{ }^{\circ} \mathrm{C}$ for $3 \mathrm{~min}$, then 40 cycles of amplification at $95^{\circ} \mathrm{C}$ for $30 \mathrm{~s}, 60^{\circ} \mathrm{C}$ for $30 \mathrm{~s}$, $72^{\circ} \mathrm{C}$ for $30 \mathrm{~s}$. Melting curves were obtained from $70^{\circ} \mathrm{C}$ to $95^{\circ} \mathrm{C}$ at $0.1^{\circ} \mathrm{C} / \mathrm{s}$ by continuous monitoring of fluorescent signals to check the specificity of amplicons and primers dimers. Each reaction was set in triplicate for both technical and biological to minimize any variation. Reactions were set in volume of $20 \mu \mathrm{L}$ containing $200 \mathrm{ng}$ cDNA, $15 \mu \mathrm{L} 2 \mathrm{X}$ SYBR Green supermix and $1.0 \mu \mathrm{L}(10$ $\mu \mathrm{M})$ of each primer. CT (cycle threshold) values were analyzed later using iQ5 software (Bio-Rad Ver 1.0). The cycle threshold (CT) values were exported to MS Excel for further analysis. To study the relative gene expression level, comparative ct method was adapted. The CT values were normalized with internal standard and the fold differences were calculated using delta approach (Livak and Schmittgen, 2001).

\section{RESULTS}

Physiological performance of cotton under drought: RWC from cotton leaves were found to be $70.23 \%$, $55.12 \%$ and $44.30 \%$ with plants grown at $15 \%, 10 \%$ and 5\% GH (gravimetric humidity) levels respectively. A pronounced reduction in RWC of leaves was measured at $5 \% \mathrm{GH}$ level in comparison to other treatment.

Construction of cDNA library and functional characterization of cDNA sequences: Total 800 clones were randomly selected for sequencing. After sequencing, 711 clones showed an insert size of 100-800 bp. Total 711 unigenes (Accession\# JK757087JK757798) were submitted to NCBI Genebank. NCBI BLASTN revealed that $76 \%$ (541 sequences) showed sequence similarity to known sequences. Majority of blast match hits belonged to Gossypium spp, Populus trichochorpa spp, Oryza sativa, Zea Mays, Glycine max, Medicago, Nicotiana spp, A. thaliana and Ricinus spp, Atriplex and other plant species. Similar ESTs were simultaneously annotated for their protein functions to 
categorize into their classes. The BLASTX results demonstrated 104 unigenes showing significant similarity to known genes, 82 uniESTs displaying significant similarity to genes of predicted proteins, and 22 uniESTs remain uncharacterized in NCBI database.

The gene ontology terms were further used to classify the gene products with an $E$ value $1 \mathrm{e}^{-33}$ in functional GO categories and simplified into plantspecific annotations (GO classification) to obtain additional insights into the putative functions of unigenes. Of the $104 G$. arboreum ESTs, 82 (78.84\%) were assigned GO terms in any category (biological, cellular and molecular), and the other $22(21.15 \%)$ ESTs were uncharacterized proteins without GO terms annotations. EST's which had no Arabidopis homology in NCBI genebank, failed to obtain a GO term, fell into distinct categories like uncharacterized, predicted and hypothetical proteins. We identified 82 unigenes from the 711 total ESTs, representing non-redundant unigenes, that share similarities with defense realted genes and stress response according to GO classifications. These 82 unigenes with Arabidopis based known homologs were further annotated to molecular function $30(83 \%), 62$ $(100 \%)$ to biological process and $44(100 \%)$ to cellular components. Many of the EST's in molecular function category $(53 \%)$ were associated with catalytic activity followed by binding activity (30\%), whereas the remaining ESTs were involved in structural molecule, translation and transport activity (Fig 1A). Within the category of biological process, 23 EST's (37\%) were relegated to metabolic process, $19(30 \%)$ to cellular process while others assigned to response to stimulus, biogenesis, localization and regulation (Figure 1B). Based on the cellular components, 20 (45\%) EST's contributed maximum to cell part and $10(22.7 \%)$ to macromolecule complex followed by organelle, membrane and cell junction (Figure 1C). EST's were also grouped based on the protein categories such as nucleic acid binding \& hydrolase $(19.6 \%$ each), enzyme modulator $(10.7 \%)$ followed by chaperone, transferase, isomerase, lyase, cytoskeletal, oxidoreductase, signalling, storage, membrane trafficking, carrier, transporter, cell adhesion and calcium binding protein (Figure 1D).

BLASTX results showed significant drought responsive genes (Table 2). Some of these genes revealed sequence homology with transcription factor JUNGBRUNNEN 1, WD repeat, heat shock, FRIGIDA, peroxidase $\mathrm{P} 7$, glutathione $\mathrm{S}$-transferase, potassium channel KAT1, ubiquitin carboxyl-terminal hydrolase, Ubox domain, serine/threonine kinase, polyubiquitin, Zinc finger, lysine histidine transporter, junction-mediating and regulatory, 26S protease regulatory subunit, endochitinase, metallothionein, translational activator, CBL-interacting protein, ubiquitin, calcyclin-binding, RNA-binding like proteins isoforms. The detailed descriptions of 104 unigenes was obtained by BLASTX (Table 2).

Predicted KEGG pathways and validation of differentially expressed selected unigenes: The predicted KEGG pathways included HSP20 family protein, phosphatidylinositol glycan, large subunit ribosomal protein L23e, chromodomain-helicase-DNAbinding protein, DNA polymerase delta subunit, peroxidase, DNA-3-methyladenine glycosylase II, Peptidyl-prolyl cis-trans isomerase A, phosphoglucomutase, enoyl-CoA hydratase/3hydroxyacyl-CoA dehydrogenase, translation initiation factor 1A, Ubiquitin, 1,3-beta-glucan synthase, crossover junction endonuclease EME1, 26S proteasome regulatory subunit T1, NADH dehydrogenase, carbonic anhydrase, proline iminopeptidase, calcyclin binding protein, auxin influx carrier, protein O-GlcNAc transferase, histone $\mathrm{H} 2 \mathrm{~A}$, small subunit ribosomal protein S8e, gibberellin 2oxidase, U3 small nucleolar RNA-associated protein, cell division protease, calmodulin and glutathione Stransferase (Table 3). This ultimately proves and evidence that the potential drought responsive unigenes in our study showing the BLASTX results strongly support their direct and indirect involvement in different pathways with similar role (Table 2, Table 3 ).

We selected ten ESTs with their known function in response to stresses: WD repeat ( $W D$, JK757101), FRIGIDA (FRIGIDA, JK757130), Peroxidase P7-like isoform (POX, JK757160), U-box domain (U-box, JK757206), E3 ubiquitin-protein ligase (E3LIG, JK757286), RNA-binding ( $R B P$, JK757358), calcyclinbinding ( $C B P, \mathrm{JK} 757361)$, glutathione S-transferase (GST, JK757362), endochitinase (ECHT, JK757585), metallothionein (MTT, JK757720) like proteins to further validate the expression of these genes in response to drought stress in cotton roots. The real time PCR showed significantly elevation of all 10 selected unigenes in root tissues as compared to leaf tissues. Among the 10 unigenes, WD (JK757101), was most up-regulated (223.8 fold) followed by FRIGIDA (188.40 fold), POX (100.22 fold), $U$-Box (72 fold), E3LIG (63.13 fold), RBP (53.46 fold), CBP (41.86 fold), GST (31.65 fold), ECHT (7.89 fold) and $M T T$ (6.64 fold) at $5 \%$ GH. Variable expression was measured with similar sequential pattern under 10\% GH (Fig. 2). In leaves, subjected to drought stress at $5 \% \mathrm{GH}$, the expression pattern was significantly higher than $10 \% \mathrm{GH}$ but it was significantly less than that of expression pattern observed in root tissues. WD (JK757101) showed the maximum up-regulation (51.73 fold), followed by $U$-Box (31.90), POX and FRIGIDA with similar expression level, $C B P$ and $E 3 L I G$ with similar expression pattern, RBP (18.40 fold), GST (15.81 fold), MTT (6.79) and ECHT (5.09) (Fig 2). 
Table 1. Sequences of qRT-PCR primers used in this study.

\begin{tabular}{llll}
\hline Gene & Accession no & Forward primer $\left.\mathbf{( 5}^{\prime} \mathbf{- 3}\right)$ & Reverse $\mathbf{p r i m e r}\left(\mathbf{5}^{\prime} \mathbf{-} \mathbf{3}^{\prime} \mathbf{)}\right.$ \\
\hline$W D$ & JK757101 & TTTGTTGGGGTTGCTGATCG & CAAGGGCAAAACTAAACCTGC \\
$F R I G I D A$ & JK757130 & AGAAGCAGCCACTCACCTAG & AACACACAGGCATTGCTACC \\
$P O X$ & JK757160 & TTCCTGCACCAACTTCGAAC & AATTGTTGTCCCCTGAGCCT \\
$U-B O X$ & JK757206 & AATTCTGTGCCGACAATGGG & CCAGCTTCAATCAGACAAGACC \\
$E 3 L I G$ & JK757286 & TCTCCATGTTGCCACCATCT & CAACACTACACTTGTACGCACT \\
$R B P$ & JK757358 & GCACTTGAGTCTGGTTGCAA & TTGGCGTGGTATCTCTCTCC \\
$C B P$ & JK757361 & CCTCCTTCAGCTGGGATCAA & TCACCTTGCACTTCTCTGGT \\
$G S T$ & JK757362 & GGGCAGGCTTTGGTTAATGA & ACGAAAGATTCCCGACCGAA \\
$E C H T$ & JK757585 & GCTACTGGTTTCCTGGACGA & ATGGCTTTGATGGTTGCTCC \\
$M T T$ & $\mathrm{JK} 757720$ & AAACCATCCCCTCCCTTCTC & TTCAGCTCCATCAAAGTGCG \\
\hline
\end{tabular}

Table 2. Homology analysis of the transcripts with $E$-value $<1 \mathrm{e}^{-33}$.

\begin{tabular}{|c|c|c|c|c|c|}
\hline Sequence ID & $\begin{array}{l}\text { Length } \\
\text { (bp) }\end{array}$ & Homology (blastx) & Species & Accession no & E-value \\
\hline JK757090 & 568 & Transcription factor JUNGBRUNNEN 1-like & $\begin{array}{l}\text { Gossypium } \\
\text { arboretum }\end{array}$ & XP_017614396.1 & $7 e-66$ \\
\hline JK757101 & 426 & WD repeat-containing protein like isoform & G. arboreum & XP 017621565.1 & $3 e-15$ \\
\hline JK757105 & 404 & $\begin{array}{l}\text { X1 } \\
\text { Endochitinase }\end{array}$ & G. arboreum & KHF98356.1 & $6 e-40$ \\
\hline JK757112 & 333 & Uncharacterized protein LOC107907231 & G. hirsutum & XP_016689998.1 & $3 e-7$ \\
\hline JK757113 & 731 & Heat shock protein, mitochondrial-like & G. hirsutum & XP_016721162.1 & $6 e-93$ \\
\hline JK757118 & 439 & $\begin{array}{l}\text { isoform } \mathrm{X} 2 \\
\text { Heat shock protein }\end{array}$ & G. raimondii & XP_012490256.1 & $7 e-19$ \\
\hline JK757122 & 543 & hypothetical protein F383 34022 & G. arboreum & KHG07754.1 & $2 \mathrm{e}-8$ \\
\hline JK757125 & 727 & Translation factor SUI1 homolog 2-like & G. hirsutum & XP 016728732.1 & $7 e-74$ \\
\hline JK757127 & 742 & $60 \mathrm{~S}$ ribosomal protein L23-like & G. hirsutum & $\mathrm{XP}-016747847.1$ & $9 e-94$ \\
\hline JK757130 & 497 & FRIGIDA-like protein & G. hirsutum & XP 016731871.1 & $2 \mathrm{e}-26$ \\
\hline JK757132 & 740 & DNA methylation 1-like isoform X2 & G. hirsutum & XP_016705962.1 & $5 e-40$ \\
\hline JK757132 & 375 & Uncharacterized protein LOC105785704 & G. raimondii & $\mathrm{XP}^{-} 012467285.1$ & $9 e-37$ \\
\hline JK757154 & 336 & Uncharacterized protein LOC107931081 & G. hirsutum & $\mathrm{XP}^{-} 016718360.1$ & $2 \mathrm{e}-15$ \\
\hline JK757158 & 266 & DNA polymerase delta subunit 4-like & G. raimondii & XP 012464216.1 & $2 e-9$ \\
\hline JK757160 & 760 & Peroxidase P7-like isoform X2 & G. hirsutum & $\mathrm{XP} 016724359.1$ & $9 \mathrm{e}-66$ \\
\hline JK757163 & 295 & Translationally-controlled tumor protein & G. raimondii & XP_012461134.1 & $7 e-8$ \\
\hline JK757169 & 692 & $\begin{array}{l}\text { homolog isoform X2 } \\
\text { Glutathione S-transferase F9-like }\end{array}$ & G. raimondii & XP_012461574.1 & $7 e-75$ \\
\hline JK757179 & & DNA-3-methyladenine glycosylase 1-like & G. hirsutum & XP_016689519.1 & $7 e-7$ \\
\hline JK757183 & 335 & $\begin{array}{l}\text { isoform X2 } \\
\text { Uncharacterized protein LOC107912702 }\end{array}$ & G. hirsutum & XP_016696495.1 & $3 e-4$ \\
\hline JK757186 & 300 & Potassium channel KAT1 & G. raimondii & XP_012455538.1 & $8 \mathrm{e}-32$ \\
\hline JK757189 & 423 & Putative aldo-keto reductase 1 & G. arboreum & KHG 27361.1 & $8 \mathrm{e}-22$ \\
\hline JK757194 & 431 & $\begin{array}{l}\text { Peptidyl-prolyl cis-trans isomerase CYP19-3 } \\
\text { isoform X3 }\end{array}$ & G. raimondii & XP_012464987.1 & $7 e-64$ \\
\hline JK757195 & 672 & Ubiquitin carboxyl-terminal hydrolase 2-like & G. hirsutum & XP_016739633.1 & $1 \mathrm{e}-34$ \\
\hline JK757196 & 468 & Uncharacterized protein LOC105770440 & G. raimondii & XP_012447097.1 & $4 \mathrm{e}-30$ \\
\hline JK757198 & 739 & Uncharacterized protein LOC105800056 & G. raimondii & XP_012486436.1 & $5 e-76$ \\
\hline JK757199 & 469 & Phosphatase & G. arboreum & XP_017605169.1 & $5 e-8$ \\
\hline JK757202 & 686 & Phosphoglucomutase, cytoplasmic isoform & G. raimondii & XP_012467251.1 & $4 \mathrm{e}-38$ \\
\hline JK757204 & 747 & $\mathrm{X} 1$ & & & \\
\hline & & Heat shock protein & G. raimondii & XP 012445867.1 & $3 e-100$ \\
\hline JK757207 & 472 & $\begin{array}{l}\text { Peroxisomal fatty acid beta-oxidation } \\
\text { multifunctional AIM1-like }\end{array}$ & G. hirsutum & XP_016720425.1 & $8 \mathrm{e}-20$ \\
\hline JK757212 & 435 & $\begin{array}{l}\text { Heavy metal-associated isoprenylated plant } \\
\text { protein 3-like }\end{array}$ & G. hirsutum & XP_016669560.1 & $9 e-16$ \\
\hline JK757219 & 460 & Translation initiation factor $1 \mathrm{~A}-$-like & G. hirsutum & XP_016740250.1 & $8 \mathrm{e}-30$ \\
\hline JK757227 & 292 & $\begin{array}{l}\text { B3 domain-containing protein } \\
\text { Os01g0234100-like isoform X3 }\end{array}$ & G. hirsutum & XP_016678084.1 & $6 e-5$ \\
\hline JK757233 & 558 & Serine/threonine-protein kinase & G. arboreum & KHG03295.1 & $1 e-58$ \\
\hline
\end{tabular}




\begin{tabular}{|c|c|c|c|c|c|}
\hline JK757239 & 445 & Polyubiquitin & G. barbadense & AAP40646.1 & $7 e-51$ \\
\hline JK757242 & 283 & Callose synthase 7-like & G. hirsutum & XP_016678563.1 & $9 e-37$ \\
\hline JK757280 & 687 & Zinc finger protein & G. arboreum & KHG09507.1 & $2 \mathrm{e}-35$ \\
\hline JK757284 & 647 & $\begin{array}{l}\text { Endoplasmic reticulum-Golgi intermediate } \\
\text { compartment protein } 3 \text {-like }\end{array}$ & G. raimondii & XP_012464567.1 & $9 e-45$ \\
\hline JK757286 & 611 & E3 ubiquitin-protein ligase RNF170-like & G. raimondii & XP_012447413.1 & $3 e-10$ \\
\hline JK757287 & 209 & Ycf2 & G. somalense & YP_006503402.1 & $2 \mathrm{e}-4$ \\
\hline JK757291 & 714 & hypothetical protein & G. arboreum & KHG27945.1 & $4 e-22$ \\
\hline JK757296 & 334 & Lysine histidine transporter & G. arboreum & KHG11676.1 & $8 \mathrm{e}-20$ \\
\hline JK757297 & 698 & hypothetical protein & G. arboreum & KHG03575.1 & $7 e-28$ \\
\hline JK757301 & 332 & Junction mediating and regulatory protein & G. arboreum & KHG07338.1 & $3 e-4$ \\
\hline JK757302 & 421 & Coatomer subunit delta-like & G. arboreum & XP_017620365.1 & $1 e-33$ \\
\hline JK757310 & 300 & STRUBBELIG-receptor family 8 isoform X1 & G. raimondii & XP_012450336.1 & $9 e-4$ \\
\hline JK757312 & 249 & 60S ribosomal protein L17-1-like & G. raimondii & $\mathrm{XP}^{-} 012487644.1$ & $7 e-11$ \\
\hline JK757316 & 677 & Uncharacterized protein LOC107953297 & G. hirsutum & XP_016744040.1 & $5 e-40$ \\
\hline JK757321 & 544 & 26S protease regulatory subunit 7-like & G. raimondii & XP_012454429.1 & $1 e-51$ \\
\hline JK757325 & 258 & NADH dehydrogenase [ubiquinone] 1 beta & G. arboreum & KHF98980.1 & $3 e-11$ \\
\hline \multirow[t]{2}{*}{ JK757329 } & 614 & subcomplex subunit 9 -like protein & & & \\
\hline & & CSC1-like protein HYP1 & G. raimondii & XP_012460084.1 & $5 e-44$ \\
\hline JK757336 & 440 & Uncharacterized protein LOC105761689 & G. raimondii & XP_012435028.1 & $5 e-29$ \\
\hline JK757341 & 600 & hypothetical protein & G. arboreum & KHG07502.1 & $7 e-21$ \\
\hline JK757346 & 313 & $\begin{array}{l}\text { beta carbonic anhydrase } 5 \text {, chloroplastic-like } \\
\text { isoform X1 }\end{array}$ & G. raimondii & XP_012445691.1 & $7 e-27$ \\
\hline JK757352 & 675 & GATA transcription factor 24-like isoform & G. hirsutum & XP_016730602.1 & $4 e-77$ \\
\hline \multirow[t]{2}{*}{ JK757357 } & 340 & $\mathrm{X} 2$ & & & \\
\hline & & $\begin{array}{l}\text { Uncharacterized vacuolar membrane protein } \\
\text { YML018C-like }\end{array}$ & G. hirsutum & XP_016710570.1 & $8 \mathrm{e}-34$ \\
\hline JK757358 & 655 & RNA-binding protein EIF1AD & G. raimondii & XP_012456238.1 & $5 e-97$ \\
\hline JK757360 & 352 & Proline iminopeptidase-like & G. hirsutum & XP_016734470.1 & $3 e-12$ \\
\hline JK757361 & 664 & Calcyclin-binding protein-like & G. raimondii & XP_012454629.1 & $5 e-91$ \\
\hline JK757362 & 572 & Glutathione S-transferase DHAR2-like & G. raimondii & XP_012455168.1 & $7 e-59$ \\
\hline JK757367 & 526 & Proteasome subunit alpha type-2-A-like & G. raimondii & XP_012454310.1 & $8 \mathrm{e}-90$ \\
\hline JK757371 & 570 & Auxin transport & G. arboreum & KHG12514.1 & $6 e-43$ \\
\hline JK757374 & 483 & Transcription factor DIVARICATA-like & G. hirsutum & XP_016666455.1 & $8 \mathrm{e}-14$ \\
\hline JK757374 & 401 & Prefoldin subunit 4 isoform $\mathrm{X} 2$ & G. hirsutum & XP_016725187.1 & $3 e-25$ \\
\hline JK757384 & 374 & $\begin{array}{l}\text { UDP-N-acetylglucosamine--peptide } \mathrm{N} \text { - } \\
\text { acetylglucosaminyltransferase }\end{array}$ & G. arboreum & XP_017649018.1 & $6 e-33$ \\
\hline JK757398 & 446 & Uncharacterized protein LOC105799707 & G. raimondii & XP_012485884.1 & $8 \mathrm{e}-29$ \\
\hline JK757402 & 395 & Ubiquitin-like protein & G. raimondii & XP_012476412.1 & $8 e-27$ \\
\hline JK757412 & 304 & Histone & G. arboreum & KHG21902.1 & $3 e-30$ \\
\hline JK757419 & 281 & Uncharacterized protein LOC105800880 & G. raimondii & XP_012487705.1 & $7 e-18$ \\
\hline JK757424 & 411 & 40 S ribosomal protein $\mathrm{S} 8$ & G. hirsutum & XP_016720360.1 & $3 e-37$ \\
\hline JK757435 & 650 & $26 \mathrm{~S}$ protease regulatory subunit 7 -like & G. hirsutum & XP_016688359.1 & $3 e-37$ \\
\hline JK757449 & 598 & $\begin{array}{l}\text { Gibberellin 2-beta-dioxygenase 1-like } \\
\text { isoform X2 }\end{array}$ & G. hirsutum & XP_016724318.1 & $9 \mathrm{e}-40$ \\
\hline JK757467 & 460 & Metallothionein & G. hirsutum & AAW47577.1 & $2 \mathrm{e}-31$ \\
\hline JK757481 & 726 & $\begin{array}{l}\text { Uncharacterized protein At3g06530 isoform } \\
\text { X3 }\end{array}$ & G. arboreum & XP_017604320.1 & $1 \mathrm{e}-23$ \\
\hline JK757484 & 673 & $\begin{array}{l}\text { ATP-dependent zinc metalloprotease FTSH } \\
3 \text {, mitochondrial-like }\end{array}$ & G. hirsutum & XP_016683336.1 & $5 e-85$ \\
\hline JK757486 & 380 & Oxygen regulatory nreC & G. arboreum & KHF97595.1 & $4 \mathrm{e}-14$ \\
\hline JK757487 & 691 & 40S ribosomal protein S19-3-like & G. hirsutum & XP_016692083.1 & $7 e-96$ \\
\hline JK757503 & 422 & Uncharacterized protein LOC105769242 & G. raimondii & XP_012445185.1 & $4 \mathrm{e}-17$ \\
\hline JK757507 & 369 & CBL-interacting protein kinase 2-like & G. hirsutum & XP_016724097.1 & $7 e-9$ \\
\hline JK757510 & 271 & Calcium-binding protein CML27 & G. hirsutum & $\mathrm{XP}^{-} 016691150.1$ & $8 \mathrm{e}-8$ \\
\hline JK757532 & 349 & Heat shock protein & G. hirsutum & $\mathrm{AB} \overline{\mathrm{W}} 89470.1$ & $3 e-18$ \\
\hline JK757538 & 197 & Lysine-specific demethylase & G. raimondii & XP_012468557.1 & $2 \mathrm{e}-10$ \\
\hline JK757549 & 436 & $\begin{array}{l}\text { Phosphoenolpyruvate carboxykinase }[\mathrm{ATP}] \text { - } \\
\text { like protein }\end{array}$ & G. arboreum & KHG 26562.1 & $1 \mathrm{e}-28$ \\
\hline JK757551 & 740 & Glyceraldehyde-3-phosphate dehydrogenase & G. arboreum & KHG20184.1 & $3 e-23$ \\
\hline JK757555 & 251 & Uncharacterized protein LOC105781470 & G. raimondii & XP_012461467.1 & $2 \mathrm{e}-4$ \\
\hline
\end{tabular}




\begin{tabular}{|c|c|c|c|c|c|}
\hline JK757559 & 769 & Uncharacterized protein LOC108452640 & G. arboreum & XP_017605930.1 & $3 e-105$ \\
\hline JK757560 & 687 & Translational activator & G. arboreum & KHG 25727.1 & $2 \mathrm{e}-29$ \\
\hline JK757567 & 411 & Wound-induced basic protein-like & G. raimondii & XP_012485360.1 & $2 \mathrm{e}-18$ \\
\hline JK757585 & 790 & Endochitinase & G. arboreum & KHF- 98356.1 & $4 e-55$ \\
\hline JK757587 & 692 & Glutathione S-transferase F9-like & G. hirsutum & XP_016710368.1 & $5 e-90$ \\
\hline JK757596 & 453 & Universal stress protein YxiE-like & G. hirsutum & XP_016680525.1 & $2 e-40$ \\
\hline JK757611 & 543 & $\begin{array}{l}\text { Uncharacterized protein LOC107940166 } \\
\text { isoform X1 }\end{array}$ & G. hirsutum & XP_016729086.1 & $2 \mathrm{e}-21$ \\
\hline JK757628 & 349 & uncharacterized protein LOC107916934 & G. hirsutum & XP 016701797.1 & $8 \mathrm{e}-4$ \\
\hline JK757641 & 414 & Uncharacterized protein LOC107916578 & G. hirsutum & XP_016701345.1 & $3 e-7$ \\
\hline JK757663 & 290 & $\begin{array}{l}\text { haloacid dehalogenase-like hydrolase } \\
\text { domain-containing protein Sgpp isoform X2 }\end{array}$ & G. raimondii & XP_012475757.1 & $5 e-25$ \\
\hline JK757665 & 549 & Lipid-transfer protein DIR1 & G. hirsutum & XP_01667 & $4 e-61$ \\
\hline JK757669 & 270 & Signal peptide peptidase-like 4 isoform $\mathrm{X} 4$ & G. raimondii & XP_012489957.1 & $2 \mathrm{e}-13$ \\
\hline JK757695 & 498 & Uncharacterized protein LOC105795069 & G. raimondii & $\mathrm{XP}^{-} 012479982.1$ & $6 e-43$ \\
\hline JK757698 & 325 & Pathogenesis-related protein STH-2-like & G. raimondii & XP_012457235.1 & $1 \mathrm{e}-14$ \\
\hline JK757703 & 346 & $\begin{array}{l}\text { 3-deoxy-arabino heptulosonate } 7 \text {-phosphate } \\
\text { synthase }\end{array}$ & G. hirsutum & $\mathrm{AB} \overline{\mathrm{U}} 43075.1$ & $7 e-14$ \\
\hline JK757705 & 332 & Uncharacterized protein LOC105771969 & G. raimondii & XP_012448793.1 & $9 e-11$ \\
\hline JK757710 & 390 & Elongation factor 1-alpha-like & G. hirsutum & XP_016722058.1 & $5 e-39$ \\
\hline JK757711 & 477 & Metallothionein-like protein & G. hirsutum & AAV 74186.1 & $7 e-30$ \\
\hline JK757715 & 606 & Oxygen regulatory nreC & G. arboreum & KHF97595.1 & $5 e-81$ \\
\hline JK757720 & 697 & Metallothionein-like protein 2 & G. hirsutum & XP 016749146.1 & $7 e-30$ \\
\hline
\end{tabular}

Table 3. Gene ID's along with KEGG orthologs and their associated pathways

\begin{tabular}{|c|c|c|c|c|}
\hline Gene ID (GenBank Acc) & Species & $\begin{array}{l}\text { KEGG } \\
\text { Orthology }\end{array}$ & Role & Associated Pathway(s) \\
\hline $\begin{array}{l}\text { Gh_D12G1971 } \\
\text { (JK757113) }\end{array}$ & G. hirsutum & K13993 & HSP20 family protein & $\begin{array}{l}\text { Genetic Information Processing } \\
\text { Folding, sorting and degradation } \\
\text { Protein processing in endoplasmic reticulum } \\
\text { (ko04141) }\end{array}$ \\
\hline $\begin{array}{l}\text { Gorai.005G148100 } \\
\text { (JK757118) }\end{array}$ & G. raimondii & K09487 & heat shock protein & $\begin{array}{l}\text { Protein processing in ER } \\
\text { Plant-pathogen interaction (ko04626) }\end{array}$ \\
\hline Gh_A11G2533(JK757125) & G. hirsutum & K05286 & $\begin{array}{l}\text { Phosphatidylinositol } \\
\text { glycan }\end{array}$ & $\begin{array}{l}\text { Glycosylphosphatidylinositol (GPI)-anchor } \\
\text { biosynthesis (ko00563) } \\
\text { Metabolic pathways (ko01100) }\end{array}$ \\
\hline Gh_D01G0610 (JK757127) & G. hirsutum & K02894 & $\begin{array}{l}\text { Large subunit } \\
\text { ribosomal protein } \mathrm{L} 23 \mathrm{e}\end{array}$ & $\begin{array}{l}\text { Genetic Information Processing Ribosome } \\
\text { (ko03010) }\end{array}$ \\
\hline Gh_A02G0834 (JK757132) & G. hirsutum & K11643 & $\begin{array}{l}\text { Chromodomain- } \\
\text { helicase- DNA-binding } \\
\text { protein } 4\end{array}$ & Enzymes (ko01000) \\
\hline Gorai.007G246800 & G. raimondii & K03505 & DNA polymerase delta & Purine metabolism (ko00230) \\
\hline$(\mathrm{JK} 757158)$ & & & Subunit & $\begin{array}{l}\text { Pyrimidine metabolism (ko00240) } \\
\text { Metabolic pathways (ko011000 Phenylpropanoid }\end{array}$ \\
\hline $\begin{array}{l}\text { Gh_A10G0565 } \\
\text { (JK757160) }\end{array}$ & G. hirsutum & K00430 & Peroxidase & $\begin{array}{l}\text { biosynthesis (ko00940) } \\
\text { Metabolic pathways (ko01100) } \\
\text { Biosynthesis of secondary metabolites (ko01110) }\end{array}$ \\
\hline $\begin{array}{l}\text { Gh_A05G2208 } \\
(\text { JK757179) }\end{array}$ & G. hirsutum & K01247 & $\begin{array}{l}\text { DNA-3-methyladenine } \\
\text { glycosylase II }\end{array}$ & Base excision repair (ko03410) \\
\hline $\begin{array}{l}\text { Gorai.013G120200 } \\
\text { (JK757194) }\end{array}$ & G. raimondii & K03767 & $\begin{array}{l}\text { Peptidyl-prolyl cis- } \\
\text { trans } \\
\text { isomerase A } \\
\text { (cyclophilin A) }\end{array}$ & $\begin{array}{l}\text { Cellular Processes Cell growth and death } \\
\text { (k01000) } \\
\text { Chaperones and folding catalysts Protein folding } \\
\text { catalysts } \\
\text { (ko03110) }\end{array}$ \\
\hline $\begin{array}{l}\text { Gorai.002G176200 } \\
\text { (JK757202) }\end{array}$ & G. raimondii & K01835 & Phosphoglucomutase & $\begin{array}{l}\text { Glycolysis / Gluconeogenesis (ko00010) } \\
\text { Pentose phosphate pathway (ko00030) } \\
\text { Galactose metabolism (ko00052) Fatty acid }\end{array}$ \\
\hline $\begin{array}{l}\text { Gh_A06G0549 } \\
\text { (JK757207) }\end{array}$ & G. hirsutum & K10527 & $\begin{array}{l}\text { Enoyl-CoA } \\
\text { hydratase/3- } \\
\text { hydroxyacyl-CoA }\end{array}$ & degradation (ko00071) \\
\hline
\end{tabular}




\begin{tabular}{|c|c|c|c|c|}
\hline & & & Dehydrogenase & Metabolic pathways (ko01100) \\
\hline & & & & Biosynthesis of secondary metabolites (ko01110) \\
\hline Gh_D07G1907 & G. hirsutum & K03236 & $\begin{array}{l}\text { Translation initiation } \\
\text { factor }\end{array}$ & RNA transport (ko03013) \\
\hline$(\mathrm{JK} 757219)$ & & & $1 \mathrm{~A}$ & \\
\hline $\begin{array}{l}\text { GOBAR_AA01294 } \\
\text { (JK757239) }\end{array}$ & G. barbadense & K08770 & Ubiquitin $\mathrm{C}$ & PPAR signaling pathway (ko03320) \\
\hline Gh_A04G1282 (JK757240) & G. hirsutum & K00706 & $\begin{array}{l}1,3 \text {-beta-glucan } \\
\text { synthase }\end{array}$ & Starch and sucrose metabolism (ko00500) \\
\hline $\begin{array}{l}\text { Cotton_A_25070 } \\
(\text { JK } 757301)\end{array}$ & G. arboreum & K10882 & $\begin{array}{l}\text { Crossover junction } \\
\text { endonuclease EME1 }\end{array}$ & Homologous recombination (ko03440) \\
\hline $\begin{array}{l}\text { Gorai.004G276000 } \\
\text { (JK757312) }\end{array}$ & G. raimondii & K02880 & $\begin{array}{l}\text { Large subunit } \\
\text { ribosomal protein } \mathrm{L} 17 \mathrm{e}\end{array}$ & Ribosome (ko03010) \\
\hline $\begin{array}{l}\text { Gorai.009G148400 } \\
\text { (JK757321) }\end{array}$ & G. raimondii & K03061 & $\begin{array}{l}26 \mathrm{~S} \text { proteasome } \\
\text { regulatory } \\
\text { subunit } \mathrm{T} 1\end{array}$ & Proteasome (ko03050) \\
\hline $\begin{array}{l}\text { Cotton_A_27223 } \\
(\text { JK757325) }\end{array}$ & G. arboreum & K03965 & $\begin{array}{l}\text { NADH dehydrogenase } \\
\text { (ubiquinone) }\end{array}$ & $\begin{array}{l}\text { Oxidative phosphorylation (ko00190) Metabolic } \\
\text { pathways (ko01100) }\end{array}$ \\
\hline Gh D12G0388 (JK757360) & G. hirsutum & K01259 & Carbonic anhydrase & Nitrogen metabolism (ko00910) \\
\hline $\begin{array}{l}\text { Gorai.009G154900 } \\
\text { (JK757361) }\end{array}$ & G. raimondii & K04507 & Proline iminopeptidase & Arginine and proline metabolism (ko00330) \\
\hline Gorai.009G152300 & G. raimondii & K02726 & $\begin{array}{l}\text { Calcyclin binding } \\
\text { protein }\end{array}$ & Wnt signaling pathway (ko04310) \\
\hline$(\mathrm{JK} 757367)$ & & & & \\
\hline Cotton_A_22138 & G. arboreum & K13946 & $\begin{array}{l}\text { 20S proteasome } \\
\text { subunit alpha }\end{array}$ & Proteasome (ko03050) \\
\hline$(\mathrm{JK} 757371)$ & & & 2 & \\
\hline $\begin{array}{l}\text { Cotton_A_24443 } \\
\text { (JK757384) }\end{array}$ & G. arboreum & K09667 & $\begin{array}{l}\text { Auxin influx carrier } \\
\text { (AUX1 LAX family) }\end{array}$ & Plant hormone signal transduction (ko04075) \\
\hline Cotton_A_22550 & G. arboreum & K11251 & $\begin{array}{l}\text { Protein O-GlcNAc } \\
\text { transferase }\end{array}$ & Other types of O-glycan biosynthesis (ko00514) \\
\hline$(\mathrm{JK} 757412)$ & & & & \\
\hline $\begin{array}{l}\text { Gh_A13G1144 } \\
\text { (JK757424) }\end{array}$ & G. hirsutum & K02995 & Histone $\mathrm{H} 2 \mathrm{~A}$ & Necroptosis (ko04217) \\
\hline Gh_D05G1363 & G. hirsutum & K03061 & $\begin{array}{l}\text { Small subunit } \\
\text { ribosomal }\end{array}$ & Ribosome (ko03010) \\
\hline$(\mathrm{JK} 757435)$ & & & protein S8e & \\
\hline Gh_A13G1308 & G. hirsutum & K04125 & $\begin{array}{l}26 \mathrm{~S} \text { proteasome } \\
\text { regulatory }\end{array}$ & Proteasome (ko03050) \\
\hline$(\mathrm{JK} 757449)$ & & & subunit $\mathrm{T} 1$ & \\
\hline $\begin{array}{l}\text { Cotton_A_03602 } \\
(\text { JK757481) }\end{array}$ & G. arboreum & K14550 & Gibberellin 2-oxidase & Diterpenoid biosynthesis (ko00904) \\
\hline Gh_A07G1588(JK757484) & G. hirsutum & K03798 & $\begin{array}{l}\text { U3 small nucleolar } \\
\text { RNA- associated } \\
\text { protein }\end{array}$ & Ribosome biogenesis in eukaryotes (ko03008) \\
\hline Gh_D08G2451 (JK757487) & G. hirsutum & K02966 & Cell division protease & $\begin{array}{l}\text { Enzymes (ko01000), Metallo Peptidases } \\
\text { (ko01002) }\end{array}$ \\
\hline Gh_A11G0032(JK757510) & G. hirsutum & K02183 & Calmodulin & $\begin{array}{l}\text { Ras signaling pathway (ko04014) Rap1 signaling } \\
\text { pathway (ko04015) } \\
\text { MAPK signaling pathway - plant (ko04016) } \\
\text { Calcium signaling pathway (ko04020) cGMP- } \\
\text { PKG signaling pathway (ko04022) } \\
\text { cAMP signaling pathway (ko04024) } \\
\text { Phosphatidylinositol signaling system (ko04070) }\end{array}$ \\
\hline $\begin{array}{l}\text { Gh_D11G1496 } \\
(\text { JK757587) }\end{array}$ & G. hirsutum & K00799 & $\begin{array}{l}\text { Glutathione S- } \\
\text { transferase }\end{array}$ & Glutathione metabolism (ko00480) \\
\hline
\end{tabular}



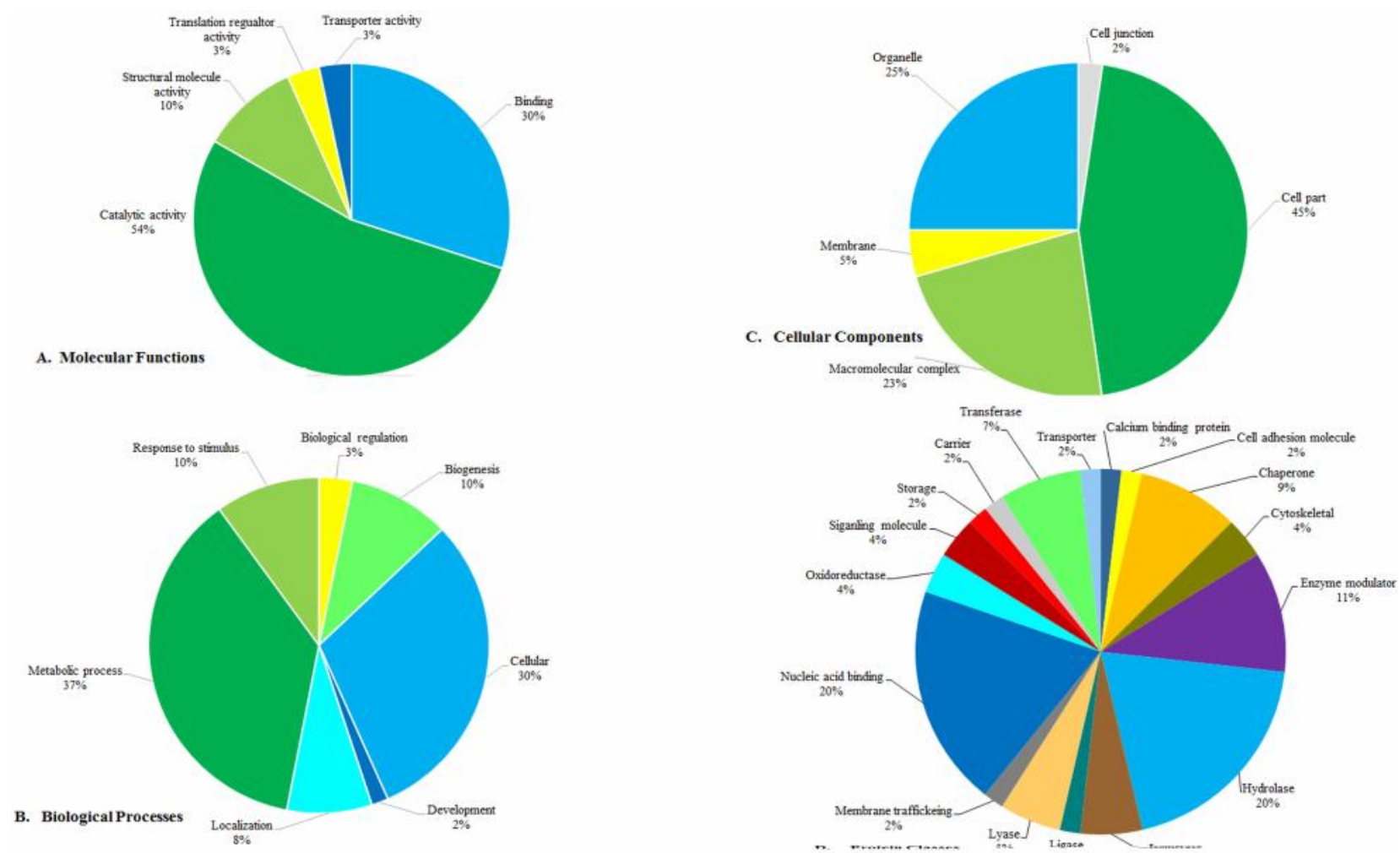

Fig 1. Functional annotation of drought stress responsive transcripts in cotton roots from cDNA library. Classification of ESTs based on (A) Cellular components, (B) Biological Processes, (C) Molecular Functions, (D) Protein classes

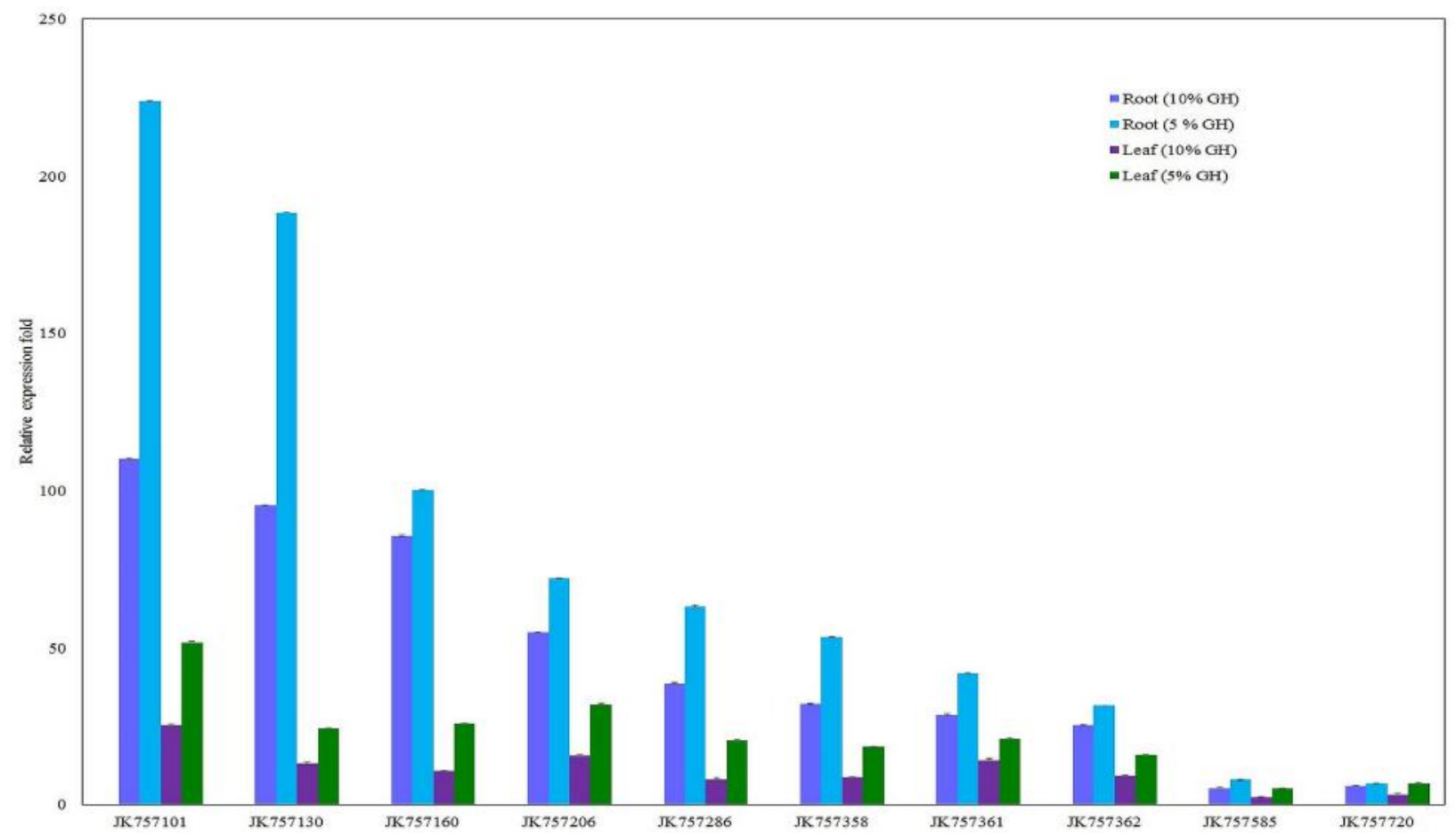

Fig 2. Relative expression of different unigenes in cotton roots as revealed by RT-qPCR.; JK757101 WD Repeat, JK757130-FRIGIDA, JK757160-Peroxidase, JK757206-U Box, JK757286-E3 Ligase, JK757358-RNA binding, JK757361-Calcyclin, JK757362-Gluathione S-transferase, JK757585-Endochitinase, JK757720Metallothionein. 


\section{DISCUSSION}

Many agro-physiological parameters related to drought tolerance have been established, RNA content, Relative water content (RWC) with decrease in water supply (Deblonde et al., 1999). The RWC is an important index in plants to measure plant water status, imitating its metabolic activity in tissues for dehydration tolerance (Anjum et al., 2011). Pronounced decline in RWC in plants leaves was observed with increasing water deficit in our study. Earlier studies also report decline in relative water contents with increase in water deprivation (Kumar et al., 2011; Meher et al., 2018). Relatively higher RWC observed in progressive mild stress than severe stress indicates that plants have the ability to sustain their water content under mild stress, whereas this ability lost under severe stress treatment in case of our findings. Alterations in RWC may be ascribed as ability of the variation to absorb more water and/or the ability to control water loss through stomata under osmotic stress (Bayoumi et al., 2008).

It is crucial to identify the differentially regulated genes and thorough understanding of stress tolerance at molecular and cellular levels (Ghorbel and Murphy, 2011). The crops whose complete genome sequence is not yet available, researchers have to opt the way by studying model genomes to explore EST sequences (Ewing et al. 1999). cDNA library constructed in our study reconnoitered drought responsive ESTs that can help in better understanding the molecular basis of drought tolerance in cotton. Overwhelming evidences also highlighted the role of stress genes and functionally efficient proteins involvement in biological processes, molecular functions and cellular structures in leaves and root tissues (Jiaa et al., 2015; Zhang et al., 2017).

Earlier cDNA libraries have been constructed for cotton related to drought responsive genes in leaves and roots (Zhang et al., 2009; Ranjan and Sawant, 2015). Still there is lack of molecular information regarding cotton root responses to drought stress. In this study, cDNA library containing 711 clones was constructed. Of these 711,82 ESTs with an $\mathrm{E}$ value $1 \mathrm{e}^{-33}$ had significant homology / similarity to reported genes in database. While remaining (22 ESTs) with uncharacterized function to any genes in Genbank databases suggesting that these uncharacterized unigenes probably embroil in abiotic stress tolerance mechanism. These unknown genes are of particular interest and can be explored further for their role, sequence and structure at protein level. In our study, though a large number of sequences were potential drought responsive transcripts. These genes were involved in the catalytic, structural molecule, cellular, metabolic, nucleic acid binding, transporter and hydrolase activities assuming their role in drought induction. This implies that we successfully constructed
cDNA library and have identified cotton root drought responsive genes.

The potential drought stress homologs engaged in biological processes reported in our study reveal their direct and / or indirect involvement in multiple stresses. Endochitinase (JK757105, JK757585) also known as EP3 chitinase has chitin binding activity and performs active biological functions in defense response, plant-type hypersensitive response, response to bacterium, wounding, somatic embryogenesis. Endochitinase being as type of pathogenesis related proteins are prompted under drought stress (Wang et al., 2016). JK757160 is peroxidase homolog (POX) P7 like protein involved in oxidative stresses. Different isoforms of POX are triggered by environmental stresses besides its involvement in plant growth and development. Various isoforms of POX are expressed under abiotic and biotic stresses (Li et al., 2009; Chiang et al., 2015). The homolog to the potassium channel (KAT) identified in this study was JK757186. KAT1 is the member of shaker family potassium ion channel located as integral membrane component and its active involvement in potassium ion transmembrane transport, membrane potential regulation and stomatal movement. Charged $\mathrm{K}^{+}$ ion channels are involved in the regulation of guard cell volume. The cytosolic phosphoglucomutase (PGM) (JK757202) identified in roots cDNA library expresses during plant growth and developmental stages. PGM being as proteins of carbon/nitrogen metabolism was reported to be more abundant in plant roots under drought stress (Mohammadi et al., 2012a; Mohammadi et al., 2012b). JK757242 in our study shows close similarity with callose synthase central role in plant development and multiple abiotic stresses. Previous findings also identified the accumulation of callose in plasma membrane in plant tissues to various biotic (wound) stresses (Chen and Kim, 2009).

In our study, few unigenes have key biological role of proteasome-mediated ubiquitin-dependent protein catabolic process. 26S protease regulatory subunit (JK757321, JK757367 and JK757435) is proteasome complex with ATPase, hydrolase and peptidyl-prolyl cistrans isomerase activity. $26 \mathrm{~S}$ proteasome required for ubiquitin-dependent degradation, plant development and stress responses (Kurepa et al., 2009). Previous report illustrate that reduced $26 \mathrm{~S}$ proteasome biogenesis results into increased hypersensitivity of heat shock while increases $26 \mathrm{~S}$ proteasome biogenesis leads to boost cell capacity to destroy oxidized proteins which ultimately leads enhance stress tolerance during oxidation (Kurepa et al., 2009).

Metallothionein (MT) (JK757467, JK757711 and JK757720) have been reported in root elongation inhibition (Zhigang et al., 2006), biotic stress resistance (Wong et al., 2004) and abiotic / metal stress tolerance (Kholodova et al., 2010). In current study, JK757596 
identified close homolog of universal stress protein (USP). USP improves the cell survival rate in response to stress when exposed to longer period of times, and may accomplish plants with broader spectrum of stress tolerance (Raphael et al., 2011). Previous findings suggest dignified involvement of USP to abiotic stresses like oxidative, salt, heat and drought (Zahur et al., 2009).

Our study enclosed few unigenes JK757125 JK757219 and JK757358 imparting their role as translation initiation factors (eIF). Previous studies reported TaeIF an overexpression in response to mild osmotic stress (Singh et al., 2007), elevated expression in roots (Yang et al., 2017), increased oxidases activities by enhancing protein synthesis and augmentation of ROS scavenging (Wang et al., 2012). EST JK757130 encodes FRIGIDA (FRI), a transcription factor functions in dehydration avoidance strategy (Lovell et al., 2013; Schmalenbach et al., 2014). Few unigenes JK757127, JK757312, JK757424 and JK757487 reported in current study are homologs to $60 \mathrm{~S}$ and $40 \mathrm{~S}$ ribosomal protein, involved in nucleic acid binding, translation and expressed during different growth and developmental plant stages. Environmental stresses regulate the ribosomal proteins and their overexpression in plants but still their abiotic stress mechanism is not very well understood (Xu et al.,2013; Liu et al., 2014). Ubiquitin carboxyl terminal based homologs JK757195 and JK757402 are engaged in hydrolase activity. The ubiquitin/26S proteasome proteolytic pathway plays an important role in development, stress responses and environmental adaptation by degrading short-lived and abnormal proteins (Hershko and Ciechanover, 1998; Callis and Vierstra, 2000). Among the unigenes involved in molecular processes, JK757233 serine threonine kinsase (SnRK) based homolog is involved in plant response to abiotic stresses, abscisic acid (ABA)dependent plant development (Afzal et al., 2008) and metabolic signalling (Halford et al., 2003).

WD repeat (JK757101) identified in this study is expressed in different plant tissues during different plant developmental stages. WD repeats proteins are key players in abiotic stresses (Lee et al., 2010). Calcineurin binding protein- interacting protein kinases (CBL- CIPK) (JK757507, JK757510) perform key role in $\mathrm{Ca}^{2+}$ signals perception besides plant development (Eckert et al., 2014). Overexpression of CBL-CIPK confers drought tolerance in plants through the regulation of stomatal movement (Wang et al., 2016). Coatomer (JK757302) is clathrin adaptor complexes medium subunit family protein located in golgi, cytosol and regulate bodies development in endosperm under drought stress (Chen et al., 2017).

cDNA library showed that $21.15 \%$ ESTs had no homology to any protein in the NCBI database. These uncharacterized ESTs may provide novel and putative candidate genes for investigation to elucidate their role in drought stress. Transcriptome studies in past unveiled the uncharacterized transcription factors (Kumar et al.,2015), hypothetical proteins (Ding et al., 2014) and uncharacterized potential sequences (Govind et al., 2009) that modulate the drought tolerance. Furthermore, the identification of uncharacterized genes as stress responsive provides a function to these genes that could not be identified under non-stressed conditions.

Cellular, biological and molecular responses of plants to these stresses have been studied intensively (Hasegawa et al., 2000; Xiong et al., 2002). In our studies, we found different categories of genes had variable and differential expression in both roots and leaves tissues. Few unigenes affianced in biological processes showed an over expression under osmotic stress. We confirm the presence of cotton peroxidases (POX; JK757160) supposedly involved in abiotic stress responses of roots and leaves with a real time quantitative PCR (RT-qPCR) in root and investigate their role in under osmotic stress as reported earlier (Csiszár et al., 2012) suggesting that this transcripts may be components of the antioxidative defense mechanism activated especially in the drought tolerant cultivar. Another key unigene involved in biological function reported as E3 ubiquitin protein (E3LIG; JK757286) ligase found to upregulated in both roots and leaves tissues under stress that is supposed to have its functions in the drought stress response via the ABA-signaling pathway. E3 ubiquitin ligases been reported to be involved in ubiquitinationmediated degradation via the $26 \mathrm{~S}$ proteasome by regulating $\mathrm{ABA}$ receptors degradation (Li et al., 2016). Previous reports suggested an overexpression of E3LIG based regulatory components in response to drought stress in plants (Kim et al., 2014).

Gluathione S transferase (GST) gene expression patterns to abiotic stresses demonstrated in plant systems explicate their role in enhancing stresses tolerance (Edwards and Dixon, 2005). A homolog (GST; JK757362) reported in this study displayed elevated expression pattern both in roots and leaves emphasizing its role in plant acclimation towards drought tolerance. Previous findings revealed the upregulated expression of GST to multiple abiotic stresses in above ground and underground plant tissues (Diao et al.,2010; Ding et al., 2017). Our results are in accordance with previous findings assuming responsiveness of GST to abiotic stresses.Current study entails homolog Endochitinase (ECHT; JK757585) explicating its inducible expression to osmotic stress emphasizing role in plants defense mechanism (Chen et al. 1994). Elevated ECHT expression have been reported in underground and above ground plant parts to multiple abiotic stresses (Behringer et al., 2015) and induced due to soil borne fungi and confers to biotic resistance and stress (Wu et al., 2012). Our findings indicate that enhanced expression of the $E C H T$ could be responsible for the increased drought 
tolerance as supported by earlier reports Furthermore; metallothionein (MTT) based homolog JK757720 showed variable expression under osmotic stress as in plants. MTT gene family play distinct and overlapping biological processes by the regulation of gene expression or signalling networks. Higher expression was of MTT was reported in current study and this overexpression of MTT gene family results in higher tolerance against abiotic stresses in plants due to scavenging of ROS production (Xue et al., 2009).

In the second category, few transcripts involved in molecular functions assessed by real time PCR exhibited an elevated expression in cotton roots and leaves tissues. Many RBPs have been shown their involvements in abiotic stresses (Ambrosone et al., 2012; Jung et al., 2013). Increased mRNA expression of $R B P$ (JK757358) in different tissues is due to active participation of $R B P$ ABA-dependent mechanisms of response to salt and drought stress (Ambrosone et al., 2015). Another molecular function based homolog FRIGIDA (JK757130) was up-regulated expounding its role under water deficit stress. Previous studies also reported overexpression of FRIGIDA suggesting that it enhances drought tolerance accumulating proline during water stress (Chen et al., 2018).

U-box domain containing protein ( $U-B O X$ JK757206), a class of E3 ubiquitin ligases exhibited an elevated expression in our experiment as its attributed towards $U$ box role during ubiquitination, a cellular process plays an important role in the perception and signal transduction of hormone and various stress responses in higher plants (Hellmann and Estelle, 2002; $\mathrm{Xu}$ et al., 2015). Studies conducted earlier also reported strong up-regulation of $U B O X$ genes in the roots under drought and salt stress (Cho et al., 2008). Our findings are best supported by previous studies signifying $U B O X$ overexpression and enhanced drought tolerance (Liu et al., 2011). Expression of Calcyclin binding protein (CBP; JK757361), an Arabidopsis homologue of SIP (SIAHinteracting protein) was elevated in roots and leaves tissues in our studies. Increased CBP level may be due to the rapid generation of ROS primarily superoxide $\left(\mathrm{O}^{2-}\right)$ and hydrogen peroxide $\left(\mathrm{H}_{2} \mathrm{O}_{2}\right)$ and production of oxidative brust as well (Grant and Loake, 2000). Reports discussed earlier mentioned the highest expression of SIP in roots, root hairs and root tips and relatively low level in leaves, which is consistent with our studies (Kim et al., 2006).

In third category of expressed genes, WD (JK757101) was up-regulated in both roots and leaves compared to the control plants, which indicate the role of this gene during water deprivation. Increased expression of WD in plant roots with involvement in nodule formation, cell wall formation (Guerriero et al., 2015), response to hormones and abiotic stresses is well understood which supports our findings (Chuang et al., 2015).

Conclusion: We successfully constructed cDNA library from cotton roots and several potential transcripts encoding drought related proteins homology were identified. These unigenes were involved in multiple biological processes and different molecular processes under osmotic stress. Differential regulation of few drought responsive genes was validated through real time quantitative PCR. Several novel transcripts with no known functions may reveal their involvement in drought tolerance and these needs to be explore further. These genes with unknown functions need further exploration of novel mechanism that may be dynamic in cotton.

Acknowledgements: we cordially thank to the Center of Excellence in Molecular Biology (CEMB), University of the Punjab, Lahore for providing us all the necessary facilities, timely support and valuable guidance during all stages of work. Our special thanks to CEMB sequencing core facility for their valuable support and cooperation. The work was partially funded by the Higher Education Commission (HEC), Islamabad, Pakistan.

Conflict of interest: The authors declare no conflict of interest.

\section{REFERENCES}

Afzal, A. J., A. J. Wood, and D.A. Lightfoot (2008). Plant receptor-like serine threonine kinases: roles in signaling and plant defense. Mol. Plant. Microbe-Interact. 21(5):507-517.

Altschul, S. F., W. Gish, W. Miller, E. W. Myers, and D. J. Lipman (1990). Basic local alignment search tool. J. Mol. Biol. 215(3):403-410.

Ambrosone, A., A. Costa, A. Leone, and S. Grillo (2012). Beyond transcription: RNA-binding proteins as emerging regulators of plant response to environmental constraints. Plant. Sci. 182:12-18.

Ambrosone, A., G. Batelli, R. Nurcato, V. Aurilia, P. Punzo, D. K. Bangarusamy, I. Ruberti, M. Sassi, A. Leone, A. Costa, and S. Grillo (2015). The Arabidopsis RNA-binding protein AtRGGA regulates tolerance to salt and drought Stress. Plant. Physiol. 168:292-306.

Anjum, S. A., X. Xie, L. C. Wang, M. F. Saleem, C. Man, and W. Lei (2011). Morphological, physiological and biochemical responses of plants to drought stress. Afr. J. Agric. Res. 6: 2026-2032.

Ashraf, J., D. Zuo, Q. Wang, W. Malik, Y. Zhang, M. A. Abid, H. Cheng, Q. Yang, and G. Song (2018). Recent insights into cotton functional genomics: progress and future perspectives. Plant. Biotech. J. 16, 699-713. 
Bayoumi, T.Y., M. H. Eid, and E. M. Metwali (2008). Application of physiological and biochemical indices as a screening technique for drought tolerance in wheat genotypes. Afr. J. Biotech. 7(14):2341-2352.

Barrs, H. D, and P. E Weatherly (1962). A reexamination of relative turgidity for estimating water deficits in leaves. Aus. J. Biol. Sci. 15:413-428.

Barozai, M.Y., and T. Husnain (2012). Identification of biotic and abiotic stress up-regulated ESTs in Gossypium arboreum. Mol. Biol. Rep. 39(2):1011-1018.

Behringer, D., H. Zimmermann, B. Ziegenhagen, and S. Liepelt (2015). Differential gene expression reveals candidate genes for drought stress response in Abies alba (Pinaceae). PloS. ONE 10(4): e0124564.

Bowman, M.J., W. Park, P.J. Bauer, J.A. Udall, J.T. Page, J. Raney, B.E. Scheffler. D. C. Jones, B. T. Campbell (2013). RNA-Seq transcriptome profiling of upland cotton (Gossypium hirsutum L.) root tissue under water-deficit stress. PLoS ONE. 8: e82634.

Callis, J. and R. D. Vierstra (2000). Protein degradation in signaling. Curr. Opin. Plant. Biol 3(5):381386.

Chaves, M. M. and M. M. Oliveira (2004). Mechanisms underlying plant resilience to water deficits: prospects for water-saving agriculture. J. Exp. Bot. 55:2365-2384.

Chen, Q., Y. Zheng, L. Luo, Y. Yang, X. Hu, and X. Kong (2018). Functional FRIGIDA allele enhances drought tolerance by regulating the P5CS1 pathway in Arabidopsis thaliana. Biochem. Biophys. Res. Commun. 495(1): 1102-1107.

Chen, R. D., L. X. Yu, A. F. Greer, H. Cheriti, and Z. Tabaeizadeh (1994). Isolation of an osmotic stress-induced and abscisic-acid-induced gene encoding an acidic endochitinase from lycopersicon chilense. Mol.Gen.Genet. 245(2):195-202.

Chen, X.Y. and J. Y. Kim (2009). Callose synthesis in higher plants. Plant. Signal. Behav. 4(6):489492.

Chen, X.Y., Y. Yang, L. P. Ran, Z. D. Dong, E. J. Zhang, X. R. Yu, and F. Xiong (2017). Novel insights into miRNA regulation of storage protein biosynthesis during wheat caryopsis development under drought Stress. Front. Plant. Sci. 8:1707.

Chiang, C. M., L.F.O Chen, S.W Shih, and K.H Lin (2015). Expression of eggplant ascorbate peroxidase increases the tolerance of transgenic rice plants to flooding stress. J. Plant. Biochem. Biotech. 24(3):257-267.

Cho, S.K., M.Y. Ryu, C. Song, J.M. Kwak, and W.T. Kim (2008). Arabidopsis PUB22 and PUB23 are homologous U-Box E3 ubiquitin ligases that play combinatory roles in response to drought stress. Plant. Cell. 20(7):1899-1914.

Chuang, H.W., J.H. Feng, Y.L. Feng, and M.J. Wei (2015). An Arabidopsis WDR protein coordinates cellular networks involved in light, stress response and hormone signals. Plant. Sci. 241:23-31.

Csiszár, J., A. Gallé, E. Horváth, P. Dancsó, M. Gombos, Z. Váry, L. Erdei, J. Györgyey, and I. Tari (2012). Different peroxidase activities and expression of abiotic stress-related peroxidases in apical root segments of wheat genotypes with different drought stress tolerance under osmotic stress. Plant. Physiol. Biochem. 52:119-129.

Davies, W.J, and J.H. Zhang (1991). Root signals and the regulation of growth and development of plants in drying soil. Annu. Rev. Plant. Physiol. Plant. Mol. Biol. 42: 55-76.

Deblonde, P.M.K., A.J. Haverkort, and J.F. Ledent (1999). Responses of early and late potato cultivars to moderate drought conditions: Agronomic parameters and carbon isotope discrimination. Eur. J. Agron. 11(2):91-105.

Diao, G., Y. Wang, and C. Yang (2010). Functional characterization of a gluthathione $\mathrm{S}$ transferase gene from Limonium bicolor in response to several abiotic stresses. African. J. Biotech. 9(32):5060-5065.

Ding, H., Z.M. Zhang, F.F. Qin, L.X. Dai, C.J. Li, D.W. $\mathrm{Ci}$, and W.W. Song (2014). Isolation and characterization of drought-responsive genes from peanut roots by suppression subtractive hybridization. Electronic. J. Biotech. 17(6):304310.

Ding, N., A. Wang, X. Zhang, Y. Wu, R. Wang, H. Cui, R. Huang, and Y. Luo (2017). Identification and analysis of glutathione S-transferase gene family in sweet potato reveal divergent GST-mediated networks in aboveground and underground tissues in response to abiotic stresses. BMC. Plant. Biol. 17:225.

Dossa, K., M. A. Mmadi, R. Zhou, T. Zhang, R. Su, Y. Zhang, L. Wang, J. You, and X. Zhang (2019). Depicting the core transcriptome modulating multiple abiotic stresses responses in sesame (Sesamum indicum L.). Int. J. Mol. Sci. 20: 3930.

Eckert, C., J. N. Offenborn, T. Heinz, T. ArmaregoMarriott, S. Schültke, C. Zhang, S. Hillmer, M. Heilmann, K. Schumacher, R. Bock, and I. Heilmann (2014). The vacuolar calcium sensors 
CBL2 and CBL3 affect seed size and embryonic development in Arabidopsis thaliana. Plant. J 78: 146-156.

Edgerton, M.D (2009). Increasing crop productivity to meet global needs for feed, food, and fuel. Plant. Physiol. 149(1):7-13.

Edwards, R., and D.P. Dixon (2005). Plant glutathione transferases.Methods. Enzymol. 401:169-186.

Ewing, R.M., A.B. Kahla, O. Poirot, F. Lopez, S. Audic, and J.M. Claverie.(1999). Large-scale statistical analyses of rice ESTs reveal correlated patterns of gene expression. Genome. Res. 9(10):950959.

Ghorbel, M.T, and D. Murphy (2011). Suppression subtractive hybridization. In: Adalberto, Merighi, editors. Neuropeptides, Methods and Protocols. Springer Protocols pp.237-259.

Govind, G., V.T. Harshavardhan, J.K. Patricia, R. Dhanalakshmi, M. K. Senthil, N. Sreenivasulu, and Udayakumar (2009). Identification and functional validation of a unique set of drought induced genes preferentially expressed in response to gradual water stress in peanut. Mol. Genet. Genomics. 281:591-605.

Grant, J.J., and G.J. Loake (2000). Role of ROIs and cognate redox signaling in disease resistance. Plant. Physiol. 124:21-29.

Graya, S.B., and S.M. Brady (2016). Plant developmental responses to climate change. Dev. Biol. 419(1):64-77.

Grayson, M. (2013). Agriculture and drought. Nature. $501 \mathrm{~S} 1$ 10.1038/501S1a.

Guerriero, G., J.F. Hausman, and I. Ezcurra (2015). WD40-repeat proteins in plant cell wall formation: current evidence and research prospects. Front. Plant. Sci. 6:1112. doi: 10.3389/fpls.2015.01112.

Halford, N.G., S. Hey, D. Jhurreea, S. Laurie, R.S. McKibbin, M. Paul, and Y. Zhang (2003). Metabolic signaling and carbon partitioning: role of Snf1-related (SnRK1) protein kinase. J. Exp. Bot. 54:467-475.

Hasegawa, P.M., R.A. Bressan, J.K. Zhu, and H.J. Bohnert (2000). Plant cellular and molecular responses to high salinity. Annu. Rev. Plant. Physiol. Plant. Mol. Biol. 51:463-499.

Hellmann, H., and M. Estelle (2002). Plant development: regulation by protein degradation. Sci. 297(5582):793-797.

Hershko, A., and A. Ciechanover (1998). The ubiquitin system. Annu. Rev. Biochem. 67:425-479.

Isokpehi, R. D., S. S. Simmons, H. H.P. Cohly, S. I. N. Ekunwe, G. B. Begonia., and W. K. Ayensu (2011). Identification of drought-responsive universal stress proteins in viridiplantae. Bioinform. Biol Insights. 5: 41-58.
Jaakola ,L., A.M. irtPtilä, M. Halonen, A. Hohtola (2001). Isolation of high quality RNA from Bilberry (Vaccinum myrtillus L.) fruit. Mol. Biotechnol. 19:201-203.

Jamal, A., M.N. Shahid, B. Aftab, B. Rashid, M.B. Sarwar, B.B. Mohamed, S. Hassan, and T. Husnain (2014). Water stress mediated changes in morphology and physiology of Gossypium arboreum (Var FDH-786). J. Plant. Sci. 2:179186.

Jiaa, D., B. Zhang, P.P. Zhang, J.Y. Zhang, Y.H. Liu, J.S. Wang, R.Y. Maa (2015). Identification of differentially expressed genes in Alternanthera philoxeroides under drought stress using suppression subtractive hybridization. Russian. J. Plant. Physiol. 62:93-100.

Jia, W., and J. Zhang (2008). Stomatal movements and long-distance signaling in plants. Plant. Signal. Behav. 3:772-777.

Jung, H.J., M.K. Kim, and H. Kang (2013). An ABAregulated putative RNA binding protein affects seed germination of Arabidopsis under ABA or abiotic stress conditions. J. Plant. Physiol. 170:179-184.

Kholodova, V., K. Volkov, and V. Kuznetsov (2010). Plants under heavy metal stress in saline environments, In: I. Sherameti, A. Varma, editors. Soil heavy metals, Soil Biology. 19. Springer Berlin Heidelberg, pp. 163-183.

Kim, H., K. Lee, H. Hwang, N. Bhatnagar, D.Y. Kim, I.S. Yoon, M.O. Byun, S.T. Kim, K.H. Jung, and B.G. Kim (2014). Overexpression of PYL5 in rice enhances drought tolerance, inhibits growth, and modulates gene expression. J. Exp. Biol. 65:453-464.

Kim, Y.S., B.K. Ham, K.H. Paek, C.M. Park, and N.H. Chua (2006). An Arabidopsis homologue of human seven-in-absentia interacting protein is involved in pathogen resistance. Mol. Cells. 21(3):389-394.

Kumar, R.R., K. Karajol, and G.R. Naik (2011). Effect of polyethylene glycol induced water stress on physiological and biochemical responses in pigeonpea (Cajanus cajan L. Millsp.). Recent. Res. Sci. Technol. 3(1):148-152.

Kumar, R.R., S. Yadav, D. Shrinivas, A.K. Srivastava, V. Shitole, and G.R. Naik (2015). Transcriptome of Pigeonpea roots under water deficit analyzed by suppression subtractive hybridization. J. Agr. Sci. Tech. 17:1333-1345.

Kurepa, J., S. Wang, Y. Li, and J. Smalle (2009). Proteasome regulation, plant growth and stress tolerance. Plant. Signal. Behav. 4(10):924-927.

Lawlor, D.W (2013). Genetic engineering to improve plant performance under drought: physiological 
evaluation of achievements, limitations, and possibilities. J. Exp. Bot. 64(1):83-108.

Lee, S., J. Lee, K.H. Paek S.Y. Kwon, H. S. Cho, S. J. Kim, and J. M. Park (2010). A novel WD40 protein, BnSWD1, is involved in salt stress in Brassica napus. Plant. Biotech. Rep. 4(2):16572.

Li, S., H. Chen, Z. Hou, Y. Li, C. Yang, D. Wang, C.P. Song (2019). Screening of abiotic stressresponsive cotton genes using a cotton fulllength cDNA overexpressing Arabidopsis library. J. Integr. Plant. Biol. doi: 10.1111/jipb.12861.

Liu, Y.C., Y.R. Wu, X.H. Huang, J. Sun, and Q. Xie (2011). AtPUB19, a U-box E3 ubiquitin ligase, negatively regulates abscisic acid and drought responses in Arabidopsis thaliana. Mol. Plant. 4(6):938-946.

Li, Y.J., R.L. Hai, X.H. Du, X.N. Jiang, and H. Lu (2009). Over-expression of a Populus peroxisomal ascorbate peroxidase (PpAPX) gene in tobacco plants enhances stress tolerance. Plant. Breed. 128(4):404-410.

Li, M., Y. Li, J. Zhao, H. Liu, S. Jia, , J. Li, H. Zhao, S. Han, Y. Wang (2016). GpDSR7, a Novel E3 ubiquitin ligase gene in Grimmia pilifera is involved in tolerance to drought stress in Arabidopsis. PLoS ONE 11:e0155455.

Lim, C.W., C. Park, J.H. Kim, H. Joo, E. Hong, and S.C. Lee (2017). Pepper CaREL1, a ubiquitin E3 ligase, regulates drought tolerance via the ABAsignalling pathway. Sci. Rep. 7:477.

Liu, X.D., L. Xie, Y. Wei, X. Zhou, B. Jia, and J. Liu (2014). Abiotic stress resistance, a novel moonlighting function of ribosomal protein RPL44 in the halophilic fungus Aspergillus glaucus. Appl. Environ. Microbiol. 80(14):42944300 .

Livak, K.J., and T.D. Schmittgen (2001). Analysis of relative gene expression data using real-time quantitative PCR and the $2^{-\Delta \Delta C T}$ method. Methods. 25(4):402-408.

Lovell, J.T., T.E. Juenger, S.D. Michaels, J.R. Lasky, A. Platt, J.H. Richards, X. Yu, H.M. Easlon, S. Sen, J.K. McKay (2013). Pleiotropy of FRIGIDA enhances the potential for multivariate adaptation. Proc. Biol. Sci. 280(1763):20131043. 10.1098/rspb.2013.1043.

Maqbool, A., M. Zahur, M. Irfan, U. Qaiser, B. Rashid, T. Husnain, and S. Riazuddin (2007). Identification, characterization and expression of drought related alpha-crystalline heat shock protein gene (GHSP) from desi cotton (Gossypium arboreum L.). Crop. Sci. 47:24372444.
Maqbool, A., M. Zahur, M. Irfan, M. Y. Barozai, B. Rashid, T. Husnain, and S. Riazuddin (2008). Identification and expression of six drought responsive transcripts through differential display in desi cotton (Gossypium arboreum). Mol. Biol. 42: 559-565.

Meherk., P. Shivakrishna, K.A. Reddy, and D.M. Rao (2018). Effect of PEG-6000 imposed drought stress on RNA content, relative water content (RWC), and chlorophyll content in peanut leaves and roots. Saudi. J. Biol. Sci. 25(2):285-289.

Mohammadi, P.P., A. Moieni, S. Hiraga, and S. Komatsu (2012a). Organ-specific proteomic analysis of drought-stressed soybean seedlings. J. Proteomics. 75(6):1906-1923.

Mohammadi, P.P., A. Moieni, S. Komatsu (2012b). Comparative proteome analysis of drought sensitive and drought tolerant rapeseed roots and their hybrid $\mathrm{F}_{1}$ line under drought stress. Amino. Acids. 43(5):2137-2152.

OECD-FAO (2019). OECD-FAO Agricultural Outlook 2019-2028, OECD Publishing, Paris/Food and Agriculture Organization of the United Nations, Rome. https://doi.org/10.1787/agr_outlook2019-en.

Ogata, H., S. Goto, K. Sato, W .Fujibuchi, H. Bono, and M. Kanehisa (1999) KEGG: kyoto encyclopedia of genes and genomes. Nucleic. Acids. Res. 27(1):29-34.

Parida, A.K., V.S. Dagaonkar, M.S. Phalak, G. Umalkar, and L.P. Aurangabadkar (2007). Alterations in photosynthetic pigments, protein and osmotic components in cotton genotypes subjected to short-term drought stress followed by recovery. Plant. Biotechnol. Rep. 1(1):37-48.

Park, B.J., Z. Liu, A. Kanno, and T. Kameya (2005). Increased tolerance to salt and water deficit stress in transgenic lettuce (Lactuca sativa L.) by constitutive expression of LEA. Plant. Growth. Regul. 45(2):165-171.

Ramachandra, R.A., K.V. Chaitanya, and M. Vivekanandan (2004). Drought-induced responses of photosynthesis and antioxidant metabolism in higher plants. J. Plant. Physiol. 161(11):1189-1202.

Ranjan, A., and S. Sawant (2015). Genome-wide transcriptomic comparison of cotton (Gossypium herbaceum) leaf and root under drought stress. 3. Biotech. 5(4): 585-596.

Riaz, M., J. Farooq, G. Sakhawat, A. Mahmood, M. Sadiq, and M. Yaseen (2013). Genotypic variability for root/shoot parameters under water stress in some advanced lines of cotton (Gossypium hirsutum L.). Genet. Mol. Res. 12(1): 552-561. 
Sambrook, J., E.F. Fritsch, and T. Maniatis (1998). Molecular Cloning: a Laboratory Manual. Cold Spring Harbor Laboratory Press, 1998 ed Cold Spring Harbor - New York.

Schmalenbach, I., L. Zhang, M. Reymond, J.M. JiménezGómez (2014). The relationship between flowering time and growth responses to drought in the Arabidopsis Landsberg erecta $\times$ Antwerp1 population. Front. Plant. Sci. 5:609. doi: 10.3389/fpls.2014.00609.

Shahid, M.N., A. Jamal, B. Rashid, B. Aftab, and T. Husnain (2012). Identification and isolation of salt-stress responsive transcripts from Gossypium arboreum L. Turk. J. Biol. 36: 746756.

Singh, G., M. Jain, R. Kulshreshtha, J.P. Khurana, S. Kumar, and P. Singh (2007). Expression analysis of genes encoding translation initiation factor 3 subunit $g$ (TaeIF3g) and vesicleassociated membrane protein-associated protein (TaVAP) in drought tolerant and susceptible cultivars of wheat. Plant. Sci. 173(6):660-669.

Statista. (2019) https://www.statista.com/ statistics /263055/cotton-production-worldwide-by-topcountries/.

Umezawa, T., M. Fujita, Y. Fujita, K. YamaguchiShinozaki, and K. Shinozaki (2006). Engineering drought tolerance in plants: discovering and tailoring genes unlock the future. Curr. Opinion. Biotech. 17(2):113-122.

Wang, J., X. Mao, R. Wang, A. Li, G. Zhao, J. Zhao, and R. Jing (2019). Identification of wheat stressresponding genes and TaPR-1-1 function by screening a cDNA yeast library prepared following abiotic stress. Sci. Rep. 9:141.

Wang, L., C. Xu, C. Wang, and Y. Wang (2012). Characterization of a eukaryotic translation initiation factor 5A homolog from Tamarix androssowii involved in plant abiotic stress tolerance. BMC. Plant. Biol. 12:118.

Wang, W., B. Vinocur, and A. Altman (2003). Plant responses to drought, salinity and extreme temperatures: towards genetic engineering for stress tolerance. Planta. 218(1):1-14.

Wang, Y., F. Liu, Y. Ren, Y. Wang, X. Liu, W. Long, D. Wang, J. Zhu, X. Zhu, R. Jing, M. Wu, Y. Hao, L. Jiang, C. Wang, H. Wang, Y. Bao, and J. Wan (2016). GOLGI TRANSPORT 1B regulates protein export from the endoplasmic reticulum in rice endosperm cells. Plant. Cell. 28(11): 2850-2865.

Wang, Y., T. Sun, L. Tingting, M. Wang, G. Yang, X., and He, G. Y. (2016). A CBL-interacting protein kinase TaCIPK2 confers drought tolerance in transgenic tobacco plants through regulating the stomatal movement. PLoS ONE 11:e0167962.
Wong, H.L., T. Sakamoto, T. Kawasaki, K. Umemura, and K. Shimamoto (2004). Down-regulation of metallothionein, a reactive oxygen scavenger, by the small GTPase OsRac1 in rice. Plant. Physiol. 135(3):1447-1456.

Xiong, L., K.S. Schumaker, and J.K. Zhu (2002). Cell signaling during cold, drought, and salt stress. The. Plant. Cell. 14suppl: S165-S183.

Wu, B., B. Zhang, Y. Dai, L. Zhang, K. Shang-Guan, Y. Peng, Y. Zhou, and Z. Zhu (2012). Brittle Culm 15 encodes a membrane-associated chitinase-like protein required for cellulose biosynthesis in rice. Plant. Physiol. 159(4): 1440-1452.

Xu, J., X-J. Xing, Y-S. Tian, R-H. Peng, Y. Xue, W. Zhao, and Q-H. Yao (2015). Transgenic Arabidopsis plants expressing tomato glutathione s-transferase showed enhanced resistance to salt and drought stress. PLoS One. 10(9): e0136960.

Xue, T., X. Li, W. Zhu, C. Wu, G. Yang, and C. Zheng (2009). Cotton metallothionein GhMT3a, a reactive oxygen species scavenger, increased tolerance against abiotic stress in transgenic tobacco and yeast. J. Exp. Bot. 60(1):339-349.

$\mathrm{Xu}$, T., K. Lee, L. Gu, J.I. Kim, and H. Kang (2013). Functional characterization of a plastid-specific ribosomal protein PSRP2 in Arabidopsis thaliana under abiotic stress conditions. Plant. Physiol. Biochem. 73:405-411.

Yan, H., S. Kikuchi, P. Neumann, W. Zhang, Y. Wu, F. Chen, and J. Jiang (2010). Genome-wide mapping of cytosine methylation revealed dynamic DNA methylation pattern associated with genes and centromeres in rice. Plant. J. 63(3):353-365.

Yang, G., L. Yu, Y. Wang, C. Wang, and C. Gao (2017). The translation initiation factor 1A (TheIF1A) from Tamarix hispida is regulated by a Dof transcription factor and increased abiotic stress tolerance. Front. Plant. Sci. 8:513.

Zahur, M., A. Maqbool, M. Irfan, M.Y.K. Barozai, B. Rashid, and S. Riazuddin (2009). Isolation and functional analysis of cotton universal stress protein promoter in response to phytohormones and abiotic stresses. Mol. Biol. 43(4):578-585.

Zahur, M., A. Maqbool, M. Irfan, A. Jamal, M.N. Shahid, B. Aftab, T. Husnain (2012). Identification and characterization of a novel gene encoding mybbox binding zinc finger protein in Gossypium arboreum. Biologia. Plantarum. 56(4):641-647.

Zhang, L., F.G. Li, C.L. Liu, C.J. Zhang, and X.Y. Zhang (2009). Construction and analysis of cotton (Gossypium arboreum L.) drought-related cDNA library. BMC. Res. Notes. 2:120. 
Zhang, F., G. Zhu, L. Du, X. Shang, C. Cheng, B. Yang, Y. Hu, C. Cai, and W. Guo (2016). Genetic regulation of salt stress tolerance revealed by RNA-Seq in cotton diploid wild species, Gossypium davidsonii. Sci. Rep. 6:20582.

Zhang, F., Y. Zhou, M. Zhang, X. Luo, and J. Xie (2017). Effects of drought stress on global gene expression profile in leaf and root samples of Dongxiang wild rice (Oryza rufipogon). Biosci. Rep. 37(3). pii: BSR20160509.

Zhigang, A., L. Cuijie, Z. Yuangang, D. Yejie, A. Wachter, R. Gromes, and T. Rausch (2006).
Expression of BjMT2, a metallothionein 2 from Brassica juncea, increases copper and cadmium tolerance in Escherichia coli and Arabidopsis thaliana, but inhibits root elongation in Arabidopsis thaliana seedlings. J. Exp. Bot. 57:3575-3582

Zhou, B., L. Zhang, A. Ullah, X. Jin, X. Yang, X. Zhang (2016). Regulation of drought stress response multiple stress responsive genes by sequencing a normalized cDNA library from sea-land cotton (Gossypium barbadense L.). PLoS. ONE. 11(3):e0152927. 